\title{
Prediction of Climatic Variables in Enriquillo Lake (Dominican Republic) using Artificial Neuronal Network (Narx Algorithm)
}

\author{
${ }^{1}$ Virgilio A. Minino Mejia, ${ }^{2}$ Juan P. Rodriguez Miranda and ${ }^{3}$ Jhon J. Feria Diaz \\ ${ }^{1}$ Department of Basic and Environmental Sciences, \\ Technological Institute of Santo Domingo (INTEC), Dominican Republic, \\ ${ }^{2}$ Faculty of Environment and Natural Resources, Universidad Distrital Francisco Jose de Caldas, \\ Bogota D.C. Colombia \\ ${ }^{3}$ Faculty of Engineering, University of Sucre, Sincelejo, Colombia
}

\begin{abstract}
The present study establishes the prediction of climatic variables of precipitation, air temperature and relative humidity in the largest lake of the Antilles which is approximately $44 \mathrm{~m}$ below sea level and especially, the analysis of these climatic variables lies that it can affect the level of the waters of this lake.
\end{abstract}

Key words: Enriquillo Lake, precipitation, temperature, relative humidity, artificial neuron network, analysis

\section{INTRODUCTION}

Enriquillo Lake is located in the Southwest of the Dominican Republic between the Neyba and Bahoruco Mountain range sand is the largest lake in the Antilles given that it has an approximate surface area of $265 \mathrm{~km}^{2}$ with three internal Islands (Koehler et al., 2009). This lake that is approximately $44 \mathrm{~m}$ below sea level, presents flood events or increased water levels, attributed by causes such as: deforestation, effects of climate change, poor management of hydraulic infrastructure, tectonic movements, climatic events that influence in some way in the lake and that contribute in the increase of the water level internally.

To perform the prediction of the precipitation, air temperature and relative humidity variables, the technique used was the Artificial Neuronal Net (ANN) and this technique has different training algorithms like Scaled Conjugate Gradient, back propagation, Newton, Levenberg Marquardt, among others. The most common and used is back propagation but in the case of the present investigation with the one which it obtained better results was with the Scaled Conjugate Gradient (SCG). The SCG artificial neural network is a feed-forward neural network. This network is composed of in dividual processing elements called neurons that resemble to the brain neurons (Zhou et al., 2008; Diaz et al., 2017). The model of each neuron can be represented as $\mathrm{A}=\mathrm{F}(\mathrm{WP}+\mathrm{b})$ where, $\mathrm{W}=\left[\mathrm{w}_{1,1}, \mathrm{w}_{1,2}, \ldots, \mathrm{w}_{1, \mathrm{R}}\right]$ and $\mathrm{P}=\left[\mathrm{p}_{1}, \mathrm{p}_{2}, \ldots, \mathrm{p}_{\mathrm{R}}\right]$, the vector $\mathrm{P}$ are the inputs $\mathrm{W}$ is the vector of the weights of each input, the parameters $\mathrm{w}_{1, \mathrm{R}}$ and $\mathrm{b}$ are adaptive (Zhu and Hao, 2009). Each neuron adds the weighted inputs and then applies a linear or non-linear function to the resulting sumto determine the outputs. Between the most commonly used functions are the step function, sigmoid and ramp. Neurons are arranged in layers and combine through excessive connectivity. This allows the specification of multiple entry criteria and the generation of multiple exit recommendations (Zhou et al., 2008). The SCG algorithm is a non-linear optimization-algorithm based on the use of second order derivatives. The SCG algorithm finds the minimum of the function $\mathrm{F}(\mathrm{x})$ which is a sum of squares of non-linear functions:

$$
\mathrm{F}(\mathrm{x})=\frac{1}{2} \sum_{\mathrm{i}=1}^{\mathrm{m}}\left[\mathrm{f}_{\mathrm{i}}(\mathrm{x})\right]^{2}
$$

Take the Jacobian from $\mathrm{f}_{\mathrm{i}}(\mathrm{x})$ which is referred to as $\mathrm{J}_{\mathrm{i}}(\mathrm{x})$, then, the SCG method looks for the solution of $\mathrm{P}$ given by the equation:

$$
\left(J_{k}^{T} J_{k}+\lambda_{k} I\right) P_{k}=-J_{k} f_{k}
$$

where, $\lambda_{\mathrm{k}}$ are not negative scalars and $\mathrm{I}$ is the identity matrix (Gill et al., 1981). The application of artificial intelligence Artificial Neural Networks (ANN) uses in the prediction of river water quality in river basins. However, it has also been found in studies an effect of accumulated error in period of several years which even generates considerable approximation cumulative predictions in

Corresponding Author: Virgilio A. Minino Mejia, Department of Basic and Environmental Sciences, Technological Institute of Santo Domingo (INTEC), Dominican Republic 
multiple time periods, it is highly means and influent in the water quality of the watershed (West and Dellana, 2011) in the prediction of water consumption and river flows in the assessment of drinking water quality in the control of water treatment processes, management of wastewater treatment plants, groundwater purification and in the identification of water sources of water pollution in terms of dioxins and sediments in rivers, other results of studies have been established that the performance of the WWTP can be predicted through a neural network and also other studies such as shown that neural networks has out performed the regression models used in wastewater treatment plants (West and Dellana, 2011). Models of neural networks and linear statistics have been applied for the application of water management in watersheds taking into account the effluents of wastewater treatment plants and non-point sources (rainwater runoff) (Diaz et al., 2017).

For this reason in this research it considers the use of the Scaled Conjugate Gradient algorithm of the neural network technique to perform the prediction of climatic variables such as: precipitation, air temperature and relative humidity in Enriquillo Lake.

\section{MATERIALS AND METHODS}

The method used is a combination of real exact observation and knowledge of an empirical, complex situation and inductive reasoning which would consist of deriving a new knowledge from particular phenomena and knowledge already obtained and establishing propositions analyzed from their causes and real effects that is from the particular to the general. It is worth mentioning that according to, the analysis and scope of the results, the type of research is analytical-quasi-experimental, since, analyzes an event and understands in terms of its obvious aspects and also discover elements that make up the totality and connections that explain their integration, i.e., it promotes the study and deeper under standing of the event under study.

The information on precipitation, air temperature and relative humidity was obtained from the Jimani weather station of the National Meteorology Office of Dominican Republic with historical records from 1950-2015.

\section{RESULTS AND DISCUSSION}

The implementation of the artificial neural network using the SCG algorithm was obtained through the import of the data over time and then the precipitation, air temperature and relative humidity were estimated, for which the following design was established:

In Fig. 1, a block of entries was observed in the first layer with acceptable results of four layers that can be used in the second stage of network design which corresponds to a standard design of the artificial neural network known as feedforward which usually has one or more hidden layers with the respective training method,

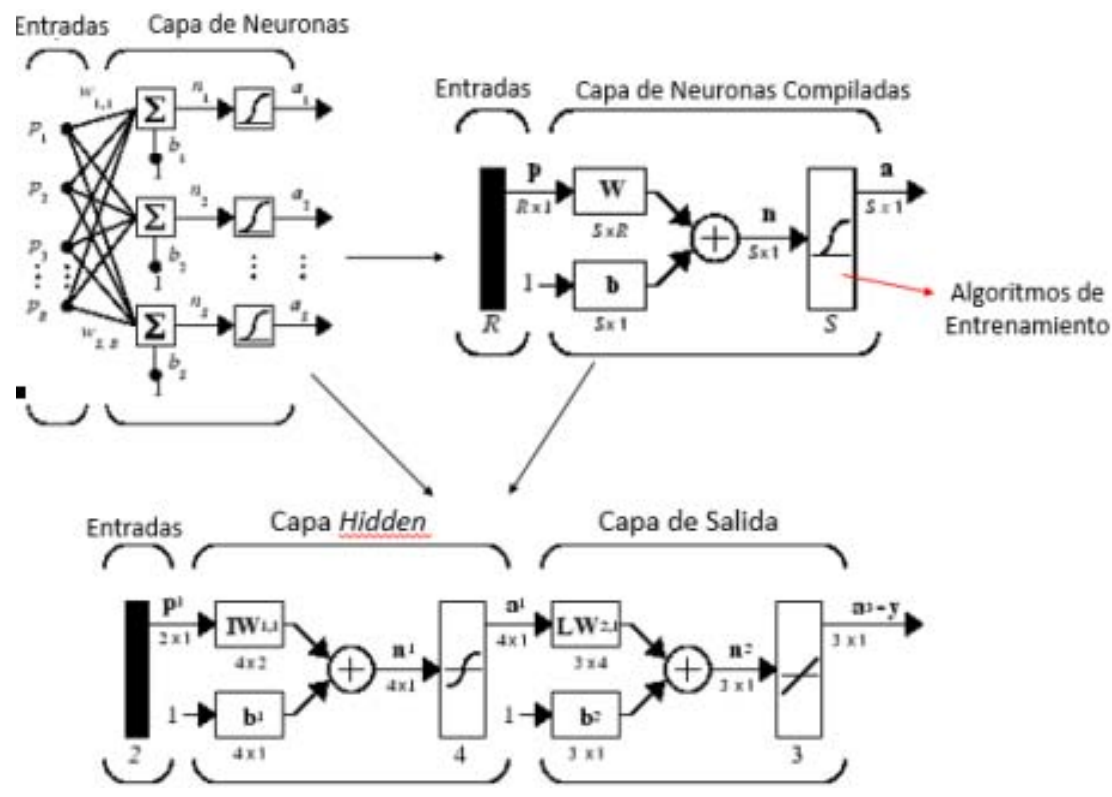

Fig. 1: Feedforward neural network proposed model (precipitation (mm) Lake Enriquillo Jimani) 
followed by a linear output layer. In terms of the training layer (hidden) it is characterized by having a training or activation criterion which can be explicitly used the SCG algorithm which has a function expressed as follows:

$$
\mathrm{F}(\mathrm{x})=\frac{1}{2} \sum_{\mathrm{i}=1}^{\mathrm{m}}\left[\mathrm{f}_{\mathrm{i}}(\mathrm{x})\right]^{2}
$$

Be the Jacobian $\mathrm{f}_{\mathrm{i}}(\mathrm{x})$ defined as $\mathrm{j}_{\mathrm{i}}(\mathrm{x})$ in such a way that the algorithm searches it eratively in the given direction, for the solutions to the required equations:

$$
\left(\mathrm{J}_{\mathrm{k}}{ }^{\mathrm{T}} \mathrm{J}_{\mathrm{k}}+\lambda_{\mathrm{k}} \mathrm{I}\right) \mathrm{p}_{\mathrm{k}}=-\mathrm{J}_{\mathrm{k}}{ }^{\mathrm{T}} \mathrm{f}_{\mathrm{k}}
$$

Where:

$\lambda_{\mathrm{k}}=$ The non-negative scalars

$\mathrm{I}=$ Corresponds to the identity matrix

Based on the above, the neuronal network is formed in MATLAB and 50 neurons were defined, the decision of the number can become subjective given the fact that, depending on the application, the decisive factor lies in the result obtained. By using the SCG neural network, you get the following:

Enriquillo Lake: In Fig. 2 and 3, the precipitation data in the Jimani station establishes a cyclical behavior of

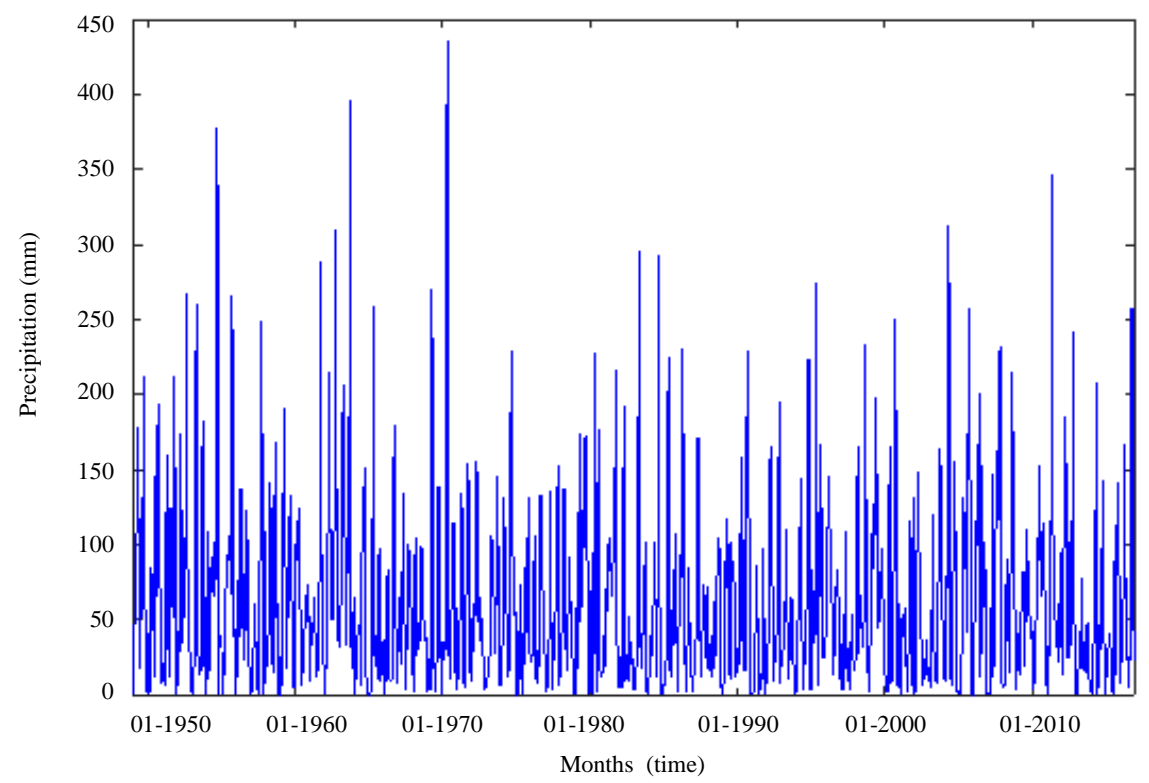

Fig. 2: Behavior of precipitation in Enriquillo Lake; Precipitacion (mm) Lake Enrriquillo-Jimani

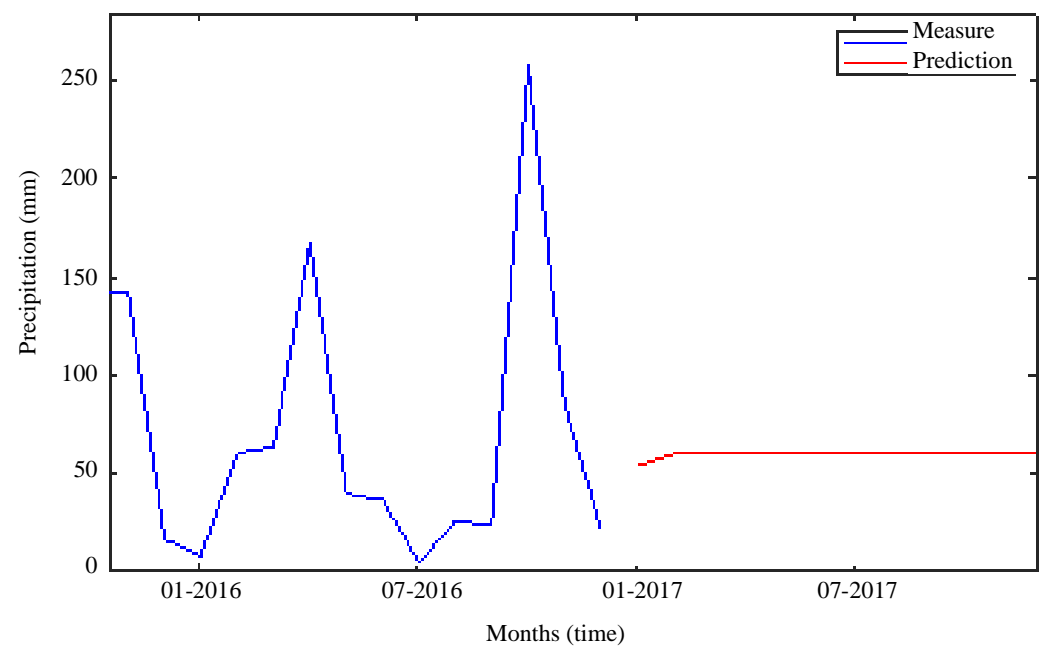

Fig. 3: Prediction of precipitation in Enriquillo Lake (Precipitation until December 2017) 
maximum values of precipitation $>300 \mathrm{~mm}$ and minimum values of $<50 \mathrm{~mm}$ in the station analyzed. On the other hand, there is a high variability considerable oscillations and heterogeneity in the precipitation data indicating that the data cloud presents a sinusoidal behavior in the period analyzed from 1950-2015.

In Fig. 3, it is observed how the line entities are the indicator of precipitation, there is a volatile fluctuation with a high recurrent frequency in the period before 2016 additional with a high dispersion of the analyzed precipitation data, however, after the prediction, a stability in the following data is obtained that is there is a little oscillation and variability in the prediction.
In Fig. 4, the maximum air temperature data at the Jimani station establishes a homogeneous, condensed behavior of medium variability given that the maximum air temperature rangeis between $30-37.5^{\circ} \mathrm{C}$ in the analyzed period from the year 1960-2015.

In Fig. 5, it is observed how the line entities is the indicator of the maximum air temperature in the preamble of historical data, they present a high variability and volatile fluctuation, however, at the time of the prediction this indicates little variability and stability in the maximum air temperature data found between $32-33.5^{\circ} \mathrm{C}$.

In Fig. 6, the relative humidity data in the Jimani station establishes heterogeneous behavior, high

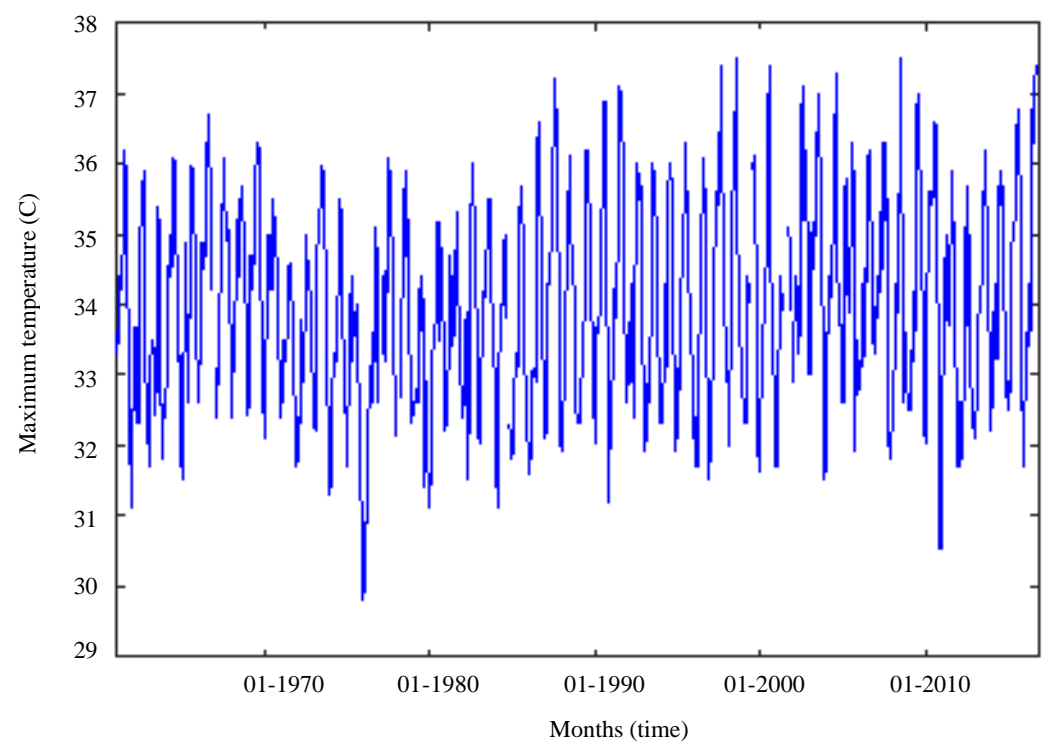

Fig. 4: Historical behavior of the maximum air temperature in Enriquillo Lake (Jimani)

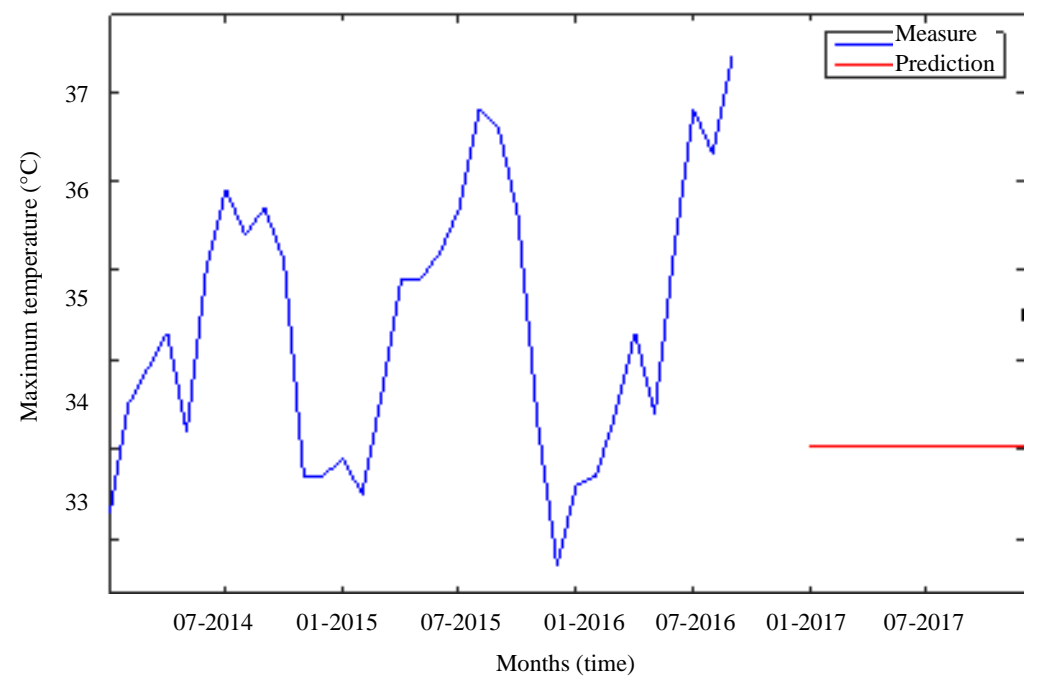

Fig. 5: Prediction of the maximum air temperature in Enriquillo Lake (Jimani, until December 2017) 


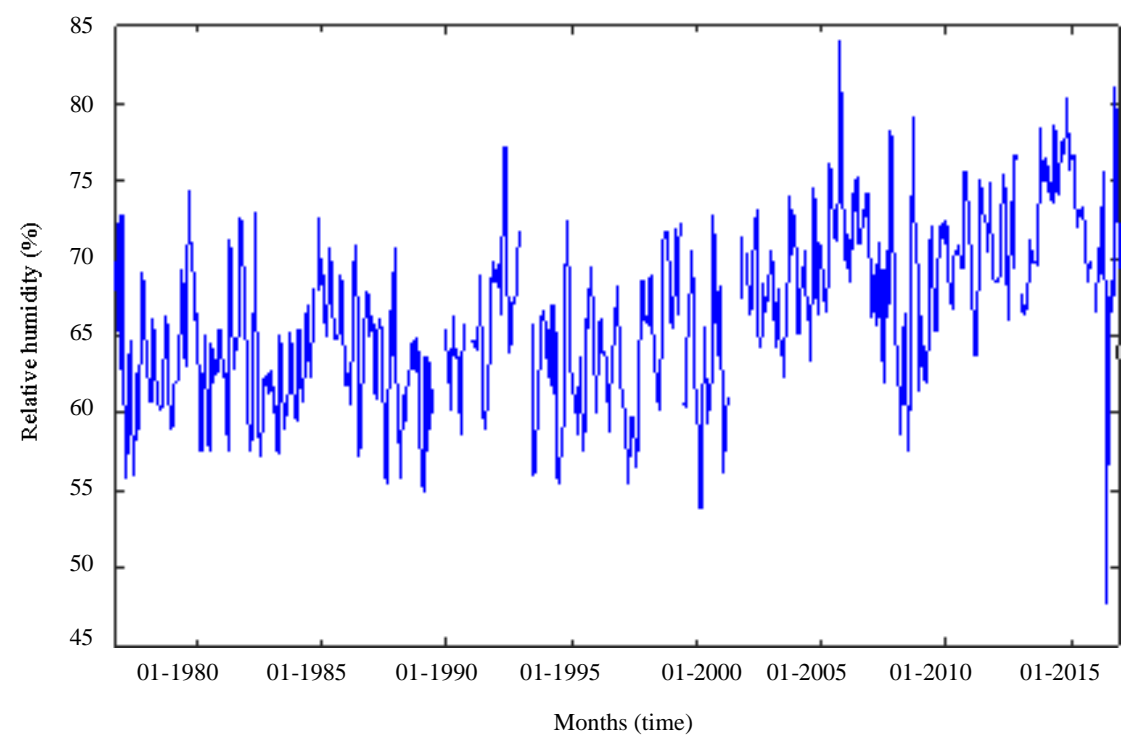

Fig. 6: Behavior of relative humidity in Enriquillo Lake (Jimani)

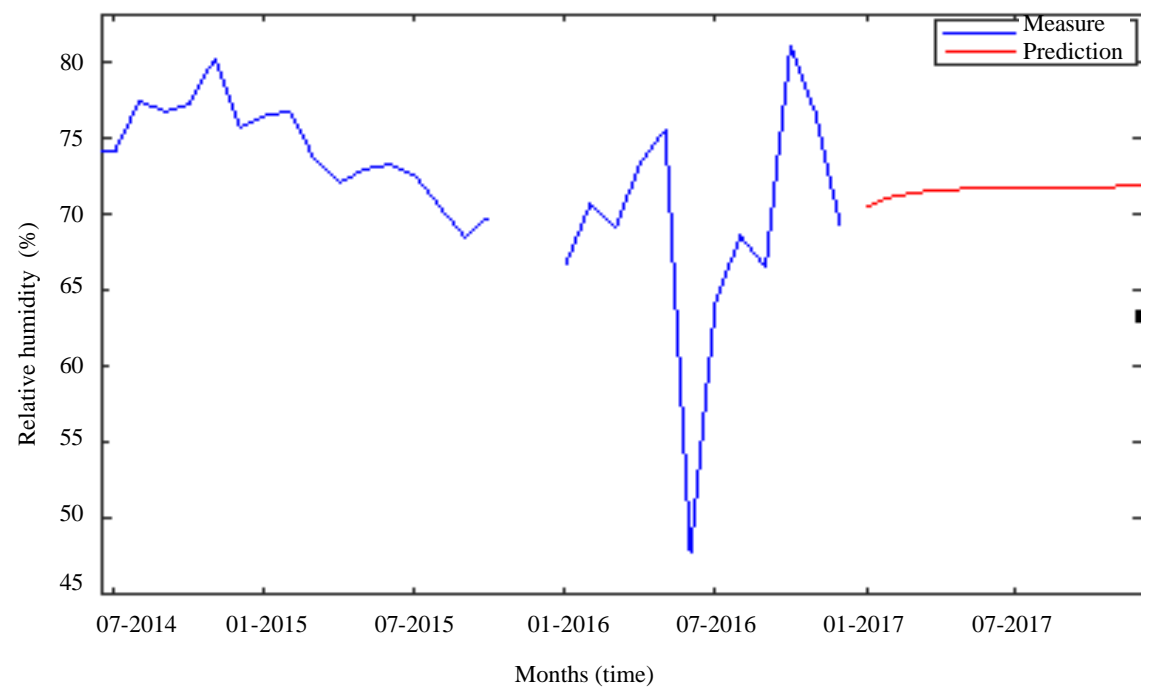

Fig. 7: Prediction of relative humidity in Enriquillo Lake (until December 2017)

variability and considerable dispersion of the data cloud given that the relative humidity interval it's found between 50 and $83 \%$ in the period analyzed from 1960-2015 (Fig 6).

In Fig. 7 , it is observed how line entities are the indicator of relative humidity in Enriquillo Lake in the preamble of historical data, they present a high variability and volatile fluctuation, however, at the time of prediction, this indicates little variability and stability in relative humidity data found between $68-72 \%$.

\section{CONCLUSION}

When using artificial neural network with the SCG algorithmto estimate the precipitation, maximum air temperature and relative humidity, a stabilized behavior is observed in the prediction of the climatic variables in the periods following the cloud of historical data obtained in the Jimani station, this means that when using compiled layers neurons and a layer of training, the result is very favorable in predicting climate variables which serves as an input to establish scenarios of making decision and behavior analysis of the Enriquillo Lake levels. 


\section{ACKNOWLEDGEMENT}

The researchers thank the National Meteorological Office in the Dominican Republic by the supplied information of the Enriquillo Lake and to the Santo Domingo Technological Institute (INTEC) for their support and cooperation with this research.

\section{REFERENCES}

Diaz, J.J.F., J.P.R. Miranda and M.A.R. Ochoa, 2017. Artificial neural network (Narx Algorithm): Prediction of dissolved Oxygen in the Sinu River (Colombia). Intl. J. Appl. Eng. Res., 12: 13215-13219.

Gill, P.R., W. Murray and M.H. Wright, 1981. The Levenberg-Marquardt Method. In: Practical Optimization, Gill, P.E., W. Murray and M.H. Wright (Eds.). Academic Press, London, UK., ISBN:9780122839504, pp: 136-137.
Koehler, R.D., P. Mann and L.A. Brown, 2009. Tectonic geomorphology and paleoseismology of strike-slip faults in Jamaica: Implications for distribution of strain and seismic hazard along the Southern edge of the Gonave microplate. Nat. Geosci., 3: 789-793.

West, D. and S. Dellana, 2011. An empirical analysis of neural network memory structures for basin water quality forecasting. Intl. J. Forecasting, 27: 777-803.

Zhou, X., W. Zhang, W. Yuan and Q. Liu, 2008. The environmental quality evaluation based on $\mathrm{BP}$ neural network and PSO and case study. Proceedings of the 2008 International Symposium on Intelligent Information Technology Application Workshops, December 21-22, 2008, IEEE, Shanghai, China, ISBN:978-0-7695-3505-0, pp: 32-35.

Zhu, C. and Z. Hao, 2009. Fuzzy neural network model and its application in water quality evaluation. Proceedings of the 2009 International Conference on Environmental Science and Information Application Technology Vol. 1, July 4-5, 2009, IEEE, Wuhan, China, ISBN:978-0-7695-3682-8, pp: 251-254. 